\title{
Negative Correlation between Placental Growth Factor and Endocan-1 in Women with Preeclampsia
}

\section{Correlação negativa entre fator de crescimento placentário e endocan-1 em mulheres com pré-eclâmpsia}

\author{
Marta Ribeiro Hentschke ${ }^{1}$ Edson Vieira da Cunha Filho ${ }^{1}$ Matias Costa Vieira ${ }^{1}$ Letícia Germany Paula ${ }^{1}$ \\ Hiten D. Mistry ${ }^{2}$ Bartira Ercília Pinheiro da Costa ${ }^{1}$ Carlos Eduardo Poli-de-Figueiredo ${ }^{1}$ \\ ${ }^{1}$ Laboratory of Nephrology, Hospital São Lucas, School of Medicine, Pontifícia \\ Universidade Católica do Rio Grande do Sul, Porto Alegre, RS, Brazil \\ 2 Division of Child Health, Obstetrics \& Gynecology, University of \\ Nottingham, Nottingham, United Kingdom \\ Address for correspondence Marta Ribeiro Hentschke, MD, PhD, \\ Laboratório de Nefrologia, Hospital São Lucas, Escola de Medicina, \\ Pontifícia Universidade Católica do Rio Grande do Sul, Av. Ipiranga \\ 6.690, 90610-000, Porto Alegre, RS, Brazil \\ (e-mail: martarh@yahoo.com.br; martahentschke@gmail.com).
}

Rev Bras Ginecol Obstet 2018;40:593-598.

\section{Abstract \\ Keywords \\ - pregnancy-induced hypertension \\ - preeclampsia \\ - endothelial function \\ - biomarkers \\ - cytokines}

\section{Resumo}

Objective To analyze endocan-1, a biomarker of vascular endothelial related pathologies, and the placental growth factor (PIGF), an angiogenic factor and a placental dysfunction marker in patients with preeclampsia (PE).

Methods Case-control study conducted at Hospital São Lucas, in the city of Porto Alegre, Brazil. Endocan-1 and PIGF levels were quantified in the maternal plasma using the MagPlexTH-C microsphere system (MAGPIX System, Luminex, Austin, Texas, US) and evaluated through analysis of covariance (ANCOVA) and adjusted by body mass index (BMI), gestational age and maternal age. To estimate the difference between the groups, the mean ratio (MR) and the $95 \%$ confidence interval $(95 \% \mathrm{Cl})$ were calculated. The Pearson correlation test was used to establish any association between endocan-1 and PIGF levels. The null hypothesis was rejected when $p<0.05$.

Results The group of patients was composed by normotensive $(n=67)$ patients and patients with PE $(n=50)$. A negative correlation between endocan- 1 and the PIGF was noted in the entire normotensive group (linear correlation coefficient $[r]=-0.605$; $p<0.001)$, as well as in the PE group $(r=-0.545 ; p<0.001)$.

Conclusion Endocan-1 levels are increased in patients with PE, and are inversely correlated with PIGF levels. We suggest that it is important to analyze angiogenic and proinflammatory molecules concomitantly in women with PE to better understand the pathophysiology of the disease. Both molecules are strong candidates for PE biomarkers, and future studies will examine any mechanisms connecting these factors in PE.

Objetivo Analisar o endocan-1, um biomarcador de patologias vasculares endoteliais, e o fator de crescimento placentário ( $F C P I)$, um fator angiogênico, marcador de disfunção placentária em pacientes com pré-eclâmpsia (PE).

Métodos Estudo de caso-controle realizado no Hospital São Lucas, em Porto Alegre. Os níveis de endocan-1 e FCPI foram quantificados no plasma materno usando o received

February 5, 2018

accepted

July 2, 2018
DOI https://doi.org/

10.1055/s-0038-1670713. ISSN 0100-7203.
Copyright $(2018$ by Thieme Revinter

Publicações Ltda, Rio de Janeiro, Brazil
License terms

(c) (1) 


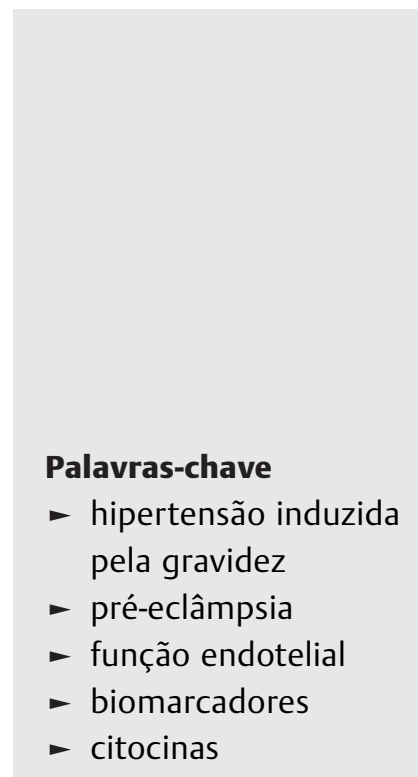

sistema de microesferas MagPlexTH-C (MAGPIX System, Luminex, Austin, Texas, US) e analisados por análise de covariância (ANCOVA) e ajustados por índice de massa corporal (IMC), idade gestacional e idade materna. Para calcular a diferença entre os grupos, utilizou-se a razão das médias (RM) e o intervalo de confiança de 95\% (IC95\%). 0 teste de correlação de Pearson foi utilizado para estabelecer a associação entre os níveis de endocan-1 e FCPI. A hipótese nula foi rejeitada quando $p<0,05$.

Resultados O grupo de pacientes foi composto por pacientes normotensas $(n=67)$ e pacientes com PE $(n=50)$. Uma correlação negativa entre o endocan-1 e o FCPI foi observada em todo o grupo de pacientes normotensas (coeficiente de correlação linear $[r]=-0,605 ; p<0,001)$, bem como no grupo com PE $(r=-0,545 ; p<0,001)$.

Conclusão Os níveis de endocan-1 estão aumentados em pacientes com PE e inversamente correlacionados com os níveis de FCPI. Sugerimos a importância de analisar moléculas angiogênicas e pró-inflamatórias concomitantemente em mulheres com PE para compreender melhor a fisiopatologia da doença. Ambas as moléculas são fortes candidatos a serem considerados biomarcadores de PE, e trabalhos futuros poderão avaliar quaisquer mecanismos que liguem esses fatores na $\mathrm{PE}$.

\section{Introduction}

Preeclampsia (PE) is one of the 3 major causes of maternal morbidity and mortality in the world, affecting 2 to $8 \%$ of all pregnancies. ${ }^{1}$ The etiology of PE remains unknown, but it is thought to begin in placentation, when there is an impairment in the vascular remodeling of the uterine spiral arteries that leads to a decrease in perfusion and high uteroplacental resistance, creating an environment of hypoxia to the placental and fetal tissues. Placental hypoxia results in the release of cytokines that, when exposed to the maternal circulation, change the vascular response, leading to widespread dysfunction of the maternal endothelium. ${ }^{2-7}$

Identifying a patient with PE is one of the major goals of prenatal care, so the patient can be referred to high-risk pregnancy protocols, with specific treatment, and, if necessary, plan the termination of the pregnancy. ${ }^{8}$

The endocan- 1 molecule is a soluble proteoglycan expressed specifically in endothelial cells. This molecule has been studied in experimental models as well as in vivo, and studies have shown that it is a possible marker and predictor of many diseases $^{9-11}$ associated with the vascular endothelium. ${ }^{9,12-21}$ Therefore, endocan-1 appears to play a key role in tumor progression and in the regulation of the inflammatory process. ${ }^{22}$

Regarding the association of endocan- 1 with PE, our group recently published a study that demonstrated a significant increase in endocan-1 levels in the maternal plasma of women with preeclampsia; ${ }^{23}$ subsequently, Chang et al. ${ }^{24}$ demonstrated the same association in the placental tissue, and Cakmak et $\mathrm{al}^{25}$ associated higher serum endocan concentrations with the severity of the disease.

A molecule that has been widely associated with the pathophysiology of diseases is the placental growth factor (PlGF). It is produced by the placenta, and has an angiogenic action. During pregnancy, the PIGF is considered a marker of placental dysfunction. Plasma concentrations of PlGF are down-regulated in patients with PE and intrauterine growth restriction (IUGR), and PIGF has been studied as a biomarker and risk predictor for the development of PE. $6,26,27$

In order to predict the chances of developing preeclampsia, it is important to associate molecules that are related both to cell growth and inflammatory cytokines, two key points of PE patients. We hypothesized that there would be a negative correlation between endocan- 1 and the PIGF. Thus, the objective of the present study was to correlate the levels of endocan-1 and PlGF in the plasma of pregnant women with and without PE.

\section{Methods}

An observational, case-control study that included pregnant women with a single fetus and with or without diagnosis of PE, who were hospitalized in Hospital São Lucas, Pontífícia Universidade Católica do Rio Grande do Sul (HSL/PUCRS, in the Portuguese acronym), in the city of Porto Alegre, Brazil, between 2010 and 2013. All samples were collected after obtaining informed written consent. The study was approved by the institution's Scientific and Ethics in Research Committee (under no. 11/05352-CEP). Preeclampsia was defined according to the National High Blood Pressure Education Program $^{28}$ and to the VI Brazilian Hypertension Guidelines ${ }^{29}$ as blood pressure $\geq 140 / 90 \mathrm{~mm} \mathrm{Hg}$, associated with pathological proteinuria $\geq 300 \mathrm{mg} / 24$ hours or a proteinuria/ creatininuria ratio $\geq 0.3$, after 20 weeks of gestation. Early onset PE was considered when the PE developed with gestational age $(\mathrm{GA})<34$ weeks. The sample was divided into two groups: one group composed of normotensive (NT) patients, and another group composed of patients with PE. The PE group was called "PE pure" after the pregnant women with superimposed PE and hemolysis, elevated liver enzymes, low platelet count (HELLP) syndrome were excluded from the analysis. 
Data from the maternal identification, the physical examination (upon hospital admission), the previous medical history, the maternal family history, the laboratory tests, the delivery, and the newborn were recorded. For both groups, women were excluded had they had a previous diagnosis of kidney disease, liver disease, active infection, multiple gestation, and/or if there was lack of information in the database.

\section{Sample Collection}

Maternal blood collection was performed after diagnosis (for the PE group) and hospitalization for delivery (for the NT group), in the third trimester of pregnancy. The final sample was composed of 117 patients (50 with PE and 67 NTs). Before delivery, $4 \mathrm{ml}$ of maternal blood were collected in ethylenediaminetetraacetic (EDTA) acid tubes. The samples were processed in the Nephrology Laboratory at HSL/PUCRS, and centrifuged at 2,000 $\mathrm{g}$ for 10 minutes, stored in $600 \mu \mathrm{l}$ aliquots first, at $-20^{\circ} \mathrm{C}$ and then at $-80^{\circ} \mathrm{C}$ until the time of analysis. Laboratory exams to evaluate the severity of the PE were conducted in the PE group.

\section{Sample Preparation}

The samples were prepared according to the instructions of the Milliplex assay kit - MagPlexTH-C assay supplier. To calculate the concentration of molecules, the MagPlexTHSystem C - microsphere assay (MAGPIX System, Luminex, Austin, Texas, US), the Milliplex kits HADK2MAG-61K-05 and HCVD1MAG-67K-02 (Millipore Corporation, Billerica, MA, US), and the XPONENT software (Luminex), version 4.2 were used. The intra-assay and inter-assay coefficient of variation was $<10 \%$. The linear correlation coefficient ( $r$ ) of the standard curve of endocan- 1 , according to the Luminex instrument, was $r=0.98$, and for the PIGF, it was $r=0.99$.

\section{Statistical Analysis}

Statistical tests were conducted using the Statistical Package for the Social Sciences (SPSS, IBM Corp. Armonk, NY, US), version 19 for Windows, the Graphpad Prism 6 (GraphPad Software, Inc., San Diego, CA, US) and the WINPEPI (PEPI-for-Windows, $($ ) J.H. Abramson, School of Public Health and Community Medicine, Hebrew University, Jerusalem, Israel). The quantitative variables were presented as mean \pm standard deviation (SD) or median and interquartile range (IQR) as appropriate, and the Mann-Whitney U-test and the Student $t$-test were used depending on the data distribution. For the categorical variables, we used percentages and applied the Chi-squared test or the Fisher exact test. Correlations between parameters were tested with the Pearson correlation coefficient. The data related to the levels of endocan- 1 and PIGF were analyzed by logarithmic transformation by analysis of covariance (ANCOVA) adjusted for body mass index (BMI), GA, and maternal age (presented as a geometric mean). In order to estimate the proportional difference of cytokines between the groups, the mean ratio (MR) and $95 \%$ confidence interval $(95 \% \mathrm{CI}$ ) were calculated. The magnitude of difference was estimated using the effect size (Cohen d). The null hypothesis was rejected when $p<0.05$.

\section{Results}

\section{Study Subjects}

The clinical and demographic characteristics, data from the physical examination, the laboratory tests and data collected at the time of delivery are presented in - Table $\mathbf{1}$. The data from the physical examination were collected on the day of admission at HSL/PUCRS.

For the clinical data, we opted to use the GA at delivery data to consider the same period of time for both groups. At the moment of the diagnosis of $\mathrm{PE}, 21$ patients were preterm (10 with GA $<34$ weeks) and 20 patients were diagnosed with severe PE due to systolic blood pressure $\geq 160 \mathrm{~mm} \mathrm{Hg}$ and/or diastolic blood pressure $\geq 110 \mathrm{~mm} \mathrm{Hg}$.

\section{Analysis of the Studied Molecules}

The mean levels of PIGF in the NT and PE pure patients were $58.4 \mathrm{pg} / \mathrm{mL}$ and $33.05 \mathrm{pg} / \mathrm{mL}$ respectively, and the mean

Table 1 Sociodemographic data and maternal and perinatal outcomes from the NT and PE groups

\begin{tabular}{|l|l|l|l|}
\hline Parameters & NT $(\mathbf{n}=\mathbf{6 7})$ & PE $(\mathbf{n}=50)$ & $p$-value \\
\hline Maternal age, years & $26 \pm 5$ & $26 \pm 6.8$ & 0.10 \\
\hline White, $\mathrm{n}(\%)$ & $34(52)$ & $31(65)$ & 0.25 \\
\hline Primiparous, $\mathrm{n}(\%)$ & $28(42)$ & $25(51)$ & 0.35 \\
\hline $\begin{array}{l}\text { Chronic } \\
\text { hypertension, } \mathrm{n}(\%)\end{array}$ & $0(0)$ & $12(24.5)$ & - \\
\hline Previous PE, $\mathrm{n}(\%)$ & $1(1.5)$ & $12(24.0)$ & - \\
\hline $\begin{array}{l}\text { BMI, kg/m } \\
\text { (weight at end of } \\
\text { the pregnancy) }\end{array}$ & $30.4 \pm 5.8$ & $32.3 \pm 5.4$ & 0.081 \\
\hline SBP, mmHg & $119 \pm 10$ & $157 \pm 17$ & $<0.001^{*}$ \\
\hline DBP, mmHg & $75 \pm 8$ & $101 \pm 14$ & $<0.001^{*}$ \\
\hline $\begin{array}{l}\text { GA at delivery, } \\
\text { weeks }\end{array}$ & $39.6 \pm 1.4$ & $36.7 \pm 3.7$ & $<0.001^{*}$ \\
\hline $\begin{array}{l}\text { Cesarean section, } \\
\mathrm{n} \text { (\%) }\end{array}$ & $22(32.8)$ & $38(76.0)$ & $<0.001^{*}$ \\
\hline 5-minute Apgar, ${ }^{* *}$ & $9.4 \pm 0.6$ & $8.72 \pm 1.21$ & $<0.001^{*}$ \\
\hline Birth weight, Kg & $3,393 \pm 458$ & $2,789 \pm 904$ & $<0.001^{*}$ \\
\hline $\begin{array}{l}\text { Placental } \\
\text { weight, Kg }\end{array}$ & $649 \pm 142$ & $590 \pm 179$ & 0.063 \\
\hline Hematocrit, \% & $35.2 \pm 2.5$ & $36.22 \pm 3.51$ & 0.14 \\
\hline Hemoglobin, g/dL & $11.6 \pm 0.9$ & $12.31 \pm 1.28$ & $0.004^{*}$ \\
\hline Platelets, mm ${ }^{3}$ (mil) & & $211.00 \pm 59.05$ & - \\
\hline Creatinine, mg/dL & $0.81 \pm 0.21$ & - \\
\hline $\begin{array}{l}\text { Proteinuria, } \\
\text { P/C rate }\end{array}$ & $0.67[0.42 ; 2.2]$ & - \\
\hline $\begin{array}{l}\text { Fasting glucose, } \\
\text { mg/dL }\end{array}$ & $75.2 \pm 9.3$ & $78.9 \pm 13.7$ & 0.26 \\
\hline
\end{tabular}

Abbreviations: BMI, body mass index; DBP, diastolic blood pressure (at admission); GA, gestational age; NT, normotensive pregnancy; P/C, proteinuria/creatininuria; PE, preeclampsia; SBP, systolic blood pressure. Notes: Data are presented as mean \pm SD (Student $t$-test), or absolute numbers and percentages (Fisher exact test), as appropriate. ${ }^{*} p<0.05$ for the NT and PE groups. ${ }^{* *}$ In the control group, in the fifth minute, no newborn had Apgar index $<7$ and in the PE group, 2 newborns received Apgar index $<7$. 

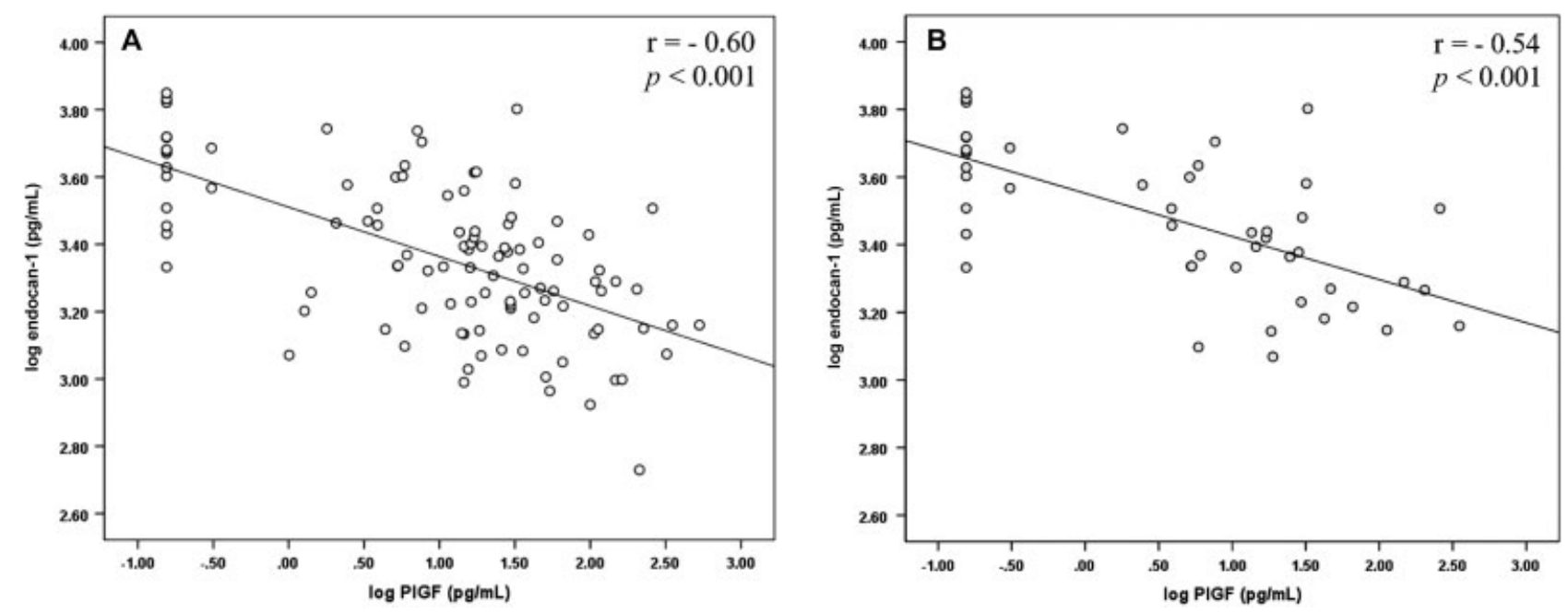

Fig. 1 Correlation between endocan-1 and the placental growth factor (PIGF). (A) Correlation between endocan-1 and the PIGF in the entire group; (B) correlation between endocan-1 and the PIGF in the PE group.

levels of endocan-1 were $2032.6 \mathrm{pg} / \mathrm{mL}$ and $3357.8 \mathrm{pg} / \mathrm{mL}$ respectively. For the statistical analysis, the logarithmic transformation was made, and the ANCOVA was applied. Lower levels of PIGF were found in the PE pure group (MR $=0.38 ; 95 \% \mathrm{CI}$ : $0.15-0.95 ; p=0.041)$, (Cohen $\mathrm{d}=0.54)$ in the maternal plasma in the PE pure group (MR $=1.56 ; 95 \%$ CI: $1.22-2,01 ; p=0.001$ ) with a moderate effect size.

When the PE group was divided into early $\mathrm{PE}(<34$ weeks of GA; $\geq 34$ weeks of GA and controls), we found in the early PE group lower levels of PIGF ( $p=0.009)$ and higher levels of endocan-1 $(p<0.001)$.

Finally, a negative correlation between endocan- 1 and the PIGF was noted in the entire NT group $(r=-0,605 ; p<0.001)$ and in the PE group $(r=-0,545 ; p<0.001)(-$ Fig. 1).

\section{Discussion}

When compared with the control group, the PIGF was 60\% lower in PE pure patients. In contrast, the level of endocan-1 between the 2 groups was 56\% higher in PE pure patients, and a strong negative correlation between the 2 molecules was observed. In the molecular analysis, the early PE group presented a statistically lower level of PIGF and higher level of endocan-1. This could suggest that both molecules may be biomarkers of early onset PE.

Many factors that may be related to PE have been proposed, but the most prominent have been associated with protein receptors of the vascular endothelial growth factor (VEGF) family, particularly the soluble vascular endothelial growth factor receptor-1(sVEGFR1) and the PIGF. ${ }^{30,31}$

The circulating PIGF in human beings is predominantly PIGF-1 (currently there are PIGFs 1 to 4 ), which is mainly produced by the placenta, and is significantly reduced in cases of $\mathrm{PE},{ }^{32,33}$ due to a negative regulation that occurs under hypoxia, ${ }^{34}$ even before the onset of the PE symptoms. ${ }^{30}$ However, the role of the PIGF in the pathogenesis of PE is not entirely known, partly because its physiologic action is not fully understood. In 2008, however, Osol et $\mathrm{al}^{35}$ demonstrated that PIGF-1 is a potent vasodilator, particularly regarding the uterine arteries, and is mediated specially by the release of nitric oxide in pregnancy, which could also regulate the venous tone. In the presence of higher levels of sVEGFR-1, the PIGF is down-regulated, which could diminish the vasodilation process and lead to hypertension, which is observed in patients with PE. ${ }^{35}$

Since the early stages of pregnancy, cell injury occurs in the extracellular matrix and in the vessel walls of the maternal decidua to create a propitious environment for embryo implantation. Ischemic lesions in the placenta resulting from poor remodeling of the decidual vessels release molecular mediators in the maternal circulation, creating an imbalance between vasoconstrictors and vasodilators, culminating in $\mathrm{PE}$ syndrome with a progressing systemic response. However, it is thought that in normal pregnancies the syncytiotrophoblast self-renews, leaving apoptotic debris in the maternal circulation, which leads to an expected inflammatory response during placental growth.

The significant increase in the concentration of endocan-1 observed in the maternal plasma might be due to this intense response to this process of physiological development, together with the increased release of proinflammatory cytokines already observed in previous studies. ${ }^{7}$

We questioned which molecule(s) would be mediating the inverse correlation found between the PIGF and endocan1 , and which one seems to change first in the pathophysiology of the disease. There is a lack of studies trying to answer this question clearly. It is known that studies that evaluated both molecules in the first trimester of pregnancy, in separate, showed that both endocan- 1 and the PIGF are decreased in patients who developed PE. ${ }^{36}$ Findings from our group demonstrated that the PIGF remains down-regulated, but endocan-1 tends to increase throughout gestation. This occurs, in part, due to the ischemia that begins and compromises the maternal circulation.

All of the patients in our study were included in the third trimester of gestation, and the level of cytokines was 
adjusted for GA to minimize the influence of this confounding factor in the results.

The placenta plays a crucial role in fetal nutrition. Endocan1 , a cytokine of predominantly inflammatory nature, injures the vasculature, and, therefore, contributes to the reduction in placental flow, IUGR, and to low placental weight.

To our knowledge, there are no complete articles in the literature that correlate these two molecules in PE.

Therefore, the study contributed to previous findings by demonstrating decreased PIGF and increased endocan- 1 in the third trimester of pregnancy in PE and its importance in cases of early onset PE. We believe that, in addition to the PIGF, a promising molecule in studies involving $\mathrm{PE}$, endocan- 1 also seems to play a role in the PE pathogenesis, and may have a relation with some clinical findings of the disease, but future researches should be performed to clarify these hypotheses.

\section{Conclusion}

The present study evaluated the presence of endocan-1 and PIGF molecules in the maternal plasma; it also correlated the levels of these cytokines in patients with PE and NT patients. In patients with PE, endocan-1 was significantly increased, and the PIGF decreased in the maternal plasma. The role of these cytokines in the pathophysiology of PE needs to be continuously studied.

\section{Contributions}

Marta Ribeiro Hentschke: substantial contributions to conception and design, data collection and analysis, and interpretation of data. Edson Vieira Cunha Filho: interpretation of data; critical review of the intellectual content; final approval of the version to be published. Matias Costa Vieira: interpretation of data; critical review of the intellectual content; final approval of the version to be published. Letícia Germany Paula: interpretation of data; critical review of the intellectual content. Hiten Mistry: substantial contributions to conception and design and interpretation of data; critical review of the intellectual content; final approval of the version to be published. Bartira Ercília Pinheiro da Costa: substantial contributions to conception and design, data collection and analysis, and interpretation of data; writing of the article or critical review of the intellectual content; and final approval of the version to be published. Carlos E. Poli-de-Figueiredo: substantial contributions to conception and design, data analysis, and interpretation of data; writing of the article or critical review of the intellectual content; final approval of the version to be published.

\section{Conflict of Interests}

The authors have none to declare.

\section{Funding and Acknowledgments}

The present study was conducted with support from Fundação de Amparo à Pesquisa do Rio Grande do Sul (Fapergs, in the Portuguese acronym), Conselho Nacional de Desenvolvimento Científico e Tecnológico (CNPq, in the Portu- guese acronym), and Coordenadoria de Aperfeiçoamento de Pessoal de Ensino Superior (Capes, in the Portuguese acronym). We would like to thank Dr. Eurico Camargo Neto for his help with the measurement and analysis of the molecules, Prof. Dr. Mario B. Wagner for statistical analysis. Poli-de-Figueiredo is a CNPq researcher.

\section{References}

1 Duley L. The global impact of pre-eclampsia and eclampsia. Semin Perinatol 2009;33(03):130-137.Doi: 10.1053/j.semperi.2009.02.010

2 Warrington JP, George EM, Palei AC, Spradley FT, Granger JP. Recent advances in the understanding of the pathophysiology of preeclampsia. Hypertension 2013;62(04):666-673. Doi: 10.1161/HYPER TENSIONAHA.113.00588

3 Lamarca B. The role of immune activation in contributing to vascular dysfunction and the pathophysiology of hypertension during preeclampsia. Minerva Ginecol 2010;62(02):105-120

4 Gilbert JS, Ryan MJ, LaMarca BB, Sedeek M, Murphy SR, Granger JP. Pathophysiology of hypertension during preeclampsia: linking placental ischemia with endothelial dysfunction. Am J Physiol Heart Circ Physiol 2008;294(02):H541-H550. Doi: 10.1152/ajp heart.01113.2007

5 Laresgoiti-Servitje E. A leading role for the immune system in the pathophysiology of preeclampsia. J Leukoc Biol 2013;94(02): 247-257. Doi: 10.1189/jlb.1112603

6 Duhig KE, Chappell LC, Shennan AH. How placental growth factor detection might improve diagnosis and management of preeclampsia. Expert Rev Mol Diagn 2014;14(04):403-406. Doi: 10.1586/14737159.2014.908121

7 Pinheiro MB, Martins-Filho OA, Mota AP, et al. Severe preeclampsia goes along with a cytokine network disturbance towards a systemic inflammatory state. Cytokine 2013;62(01):165-173. Doi: 10.1016/j.cyto.2013.02.027

8 Bewley S, Shennan A. HYPITAT and the fallacy of pregnancy interruption. Lancet 2010;375(9709):119, author reply 119-120. Doi: 10.1016/S0140-6736(10)60043-8

9 Lassalle P, Molet S, Janin A, et al. ESM-1 is a novel human endothelial cell-specific molecule expressed in lung and regulated by cytokines. J Biol Chem 1996;271(34):20458-20464. Doi: 10.1074/jbc.271.34.20458

10 Depontieu F, de Freitas Caires N, Gourcerol D, et al. Development of monoclonal antibodies and ELISA specific for the mouse vascular endocan. J Immunol Methods 2012;378(1-2):88-94. Doi: $10.1016 /$ j.jim.2012.02.009

11 Scherpereel A, Gentina T, Grigoriu B, et al. Overexpression of endocan induces tumor formation. Cancer Res 2003;63(18):6084-6089

12 Bechard D, Meignin V, Scherpereel A, et al. Characterization of the secreted form of endothelial-cell-specific molecule 1 by specific monoclonal antibodies. J Vasc Res 2000;37(05):417-425. Doi: $10.1159 / 000025758$

13 Grigoriu BD, Depontieu F, Scherpereel A, et al. Endocan expression and relationship with survival in human non-small cell lung cancer. Clin Cancer Res 2006;12(15):4575-4582. Doi: 10.1158/ 1078-0432.CCR-06-0185

14 Ziol M, Sutton A, Calderaro J, et al. ESM-1 expression in stromal cells is predictive of recurrence after radiofrequency ablation in early hepatocellular carcinoma. J Hepatol 2013;59(06):1264-1270. Doi: 10.1016/j.jhep.2013.07.030

15 Nault JC, Guyot E, Laguillier C, et al. Serum proteoglycans as prognostic biomarkers of hepatocellular carcinoma in patients with alcoholic cirrhosis. Cancer Epidemiol Biomarkers Prev 2013; 22(08):1343-1352. Doi: 10.1158/1055-9965.EPI-13-0179

$16 \mathrm{Kim}$ JH, Park MY, Kim CN, et al. Expression of endothelial cellspecific molecule- 1 regulated by hypoxia inducible factor- $1 \alpha$ in human colon carcinoma: impact of ESM-1 on prognosis and its 
correlation with clinicopathological features. Oncol Rep 2012;28 (05):1701-1708. Doi: 10.3892/or.2012.2012

17 Kang YH, Ji NY, Han SR, et al. ESM-1 regulates cell growth and metastatic process through activation of NF-KB in colorectal cancer. Cell Signal 2012;24(10):1940-1949. Doi: 10.1016/j.cellsig.2012. 06.004

18 De Freitas Caires N, Legendre B, Parmentier E, et al. Identification of a $14 \mathrm{kDa}$ endocan fragment generated by cathepsin $\mathrm{G}$, a novel circulating biomarker in patients with sepsis. J Pharm Biomed Anal 201378-79:45-51. Doi: 10.1016/j.jpba.2013.01.035

19 Paulus P, Jennewein C, Zacharowski K. Biomarkers of endothelial dysfunction: can they help us deciphering systemic inflammation and sepsis? Biomarkers 2011;16(Suppl 1):S11-S21. Doi: 10.3109/ 1354750X.2011.587893

20 Tadzic R, Mihalj M, Vcev A, Ennen J, Tadzic A, Drenjancevic I. The effects of arterial blood pressure reduction on endocan and soluble endothelial cell adhesion molecules (CAMs) and CAMs ligands expression in hypertensive patients on Ca-channel blocker therapy. Kidney Blood Press Res 2013;37(2-3):103-115. Doi: $10.1159 / 000350064$

21 Janke J, Engeli S, Gorzelniak K, et al. Adipose tissue and circulating endothelial cell specific molecule-1 in human obesity. Horm Metab Res 2006;38(01):28-33. Doi: 10.1055/s-2006-924973

22 Scherpereel A, Depontieu F, Grigoriu B, et al. Endocan, a new endothelial marker in human sepsis. Crit Care Med 2006;34(02): 532-537. Doi: 10.1097/01.CCM.0000198525.82124.74

23 Hentschke MR, Lucas LS, Mistry HD, Pinheiro da Costa BE, Poli-deFigueiredo CE. Endocan-1 concentrations in maternal and fetal plasma and placentae in pre-eclampsia in the third trimester of pregnancy. Cytokine 2015;74(01):152-156. Doi: 10.1016/j.cyto. 2015.04.013

24 Chang X, Bian Y, Wu Y, Huang Y, Wang K, Duan T. Endocan of the maternal placenta tissue is increased in pre-eclampsia. Int J Clin Exp Pathol 2015;8(11):14733-14740

25 Cakmak M, Yilmaz H, Bağlar E, et al. Serum levels of endocan correlate with the presence and severity of pre-eclampsia. Clin Exp Hypertens 2016;38(02):137-142. Doi: 10.3109/10641963.2015.1060993

26 Augustin AJ. [Placenta Growth Factor (PIGF) and Retinal Vascular Diseases-Current Knowledge from Experimental and Clinical Studies]. Klin Monatsbl Augenheilkd 2016;233(01):57-65. Doi: 10.1055/s-0041-108679
27 Chappell LC, Duckworth S, Seed PT, et al. Diagnostic accuracy of placental growth factor in women with suspected preeclampsia: a prospective multicenter study. Circulation 2013;128(19):2121-2131. Doi: 10.1161/CIRCULATIONAHA.113.003215

28 Report of the National High Blood Pressure Education Program Working Group on High Blood Pressure in Pregnancy. Am J Obstet Gynecol 2000;183(01):S1-S22. Doi: 10.1067/mob.2000. 107928

29 Brasileira de Cardiologia S, Brasileira de Hipertensão S, Brasileira de Nefrologia S; Sociedade Brasileira de Cardiologia; Sociedade Brasileira de Hipertensão; Sociedade Brasileira de Nefrologia. [VI Brazilian Guidelines on Hypertension]. Arq Bras Cardiol 2010;95 (1, Suppl)1-51. Doi: 10.1590/S0066-782X2010001700001

30 Levine RJ, Maynard SE, Qian C, et al. Circulating angiogenic factors and the risk of preeclampsia. N Engl J Med 2004;350(07): 672-683. Doi: 10.1056/NEJMoa031884

31 Bates DO. An unexpected tail of VEGF and PIGF in pre-eclampsia. Biochem Soc Trans 2011;39(06):1576-1582. Doi: 10.1042/ BST20110671

32 Reuvekamp A, Velsing-Aarts FV, Poulina IE, Capello JJ, Duits AJ. Selective deficit of angiogenic growth factors characterises pregnancies complicated by pre-eclampsia. Br J Obstet Gynaecol 1999;106(10):1019-1022. Doi: 10.1111/j.1471-0528.1999.tb0 8107.x

33 Thadhani R, Mutter WP, Wolf M, et al. First trimester placental growth factor and soluble fms-like tyrosine kinase 1 and risk for preeclampsia. J Clin Endocrinol Metab 2004;89(02):770-775. Doi: $10.1210 /$ jc.2003-031244

34 Munaut C, Lorquet S, Pequeux C, et al. Hypoxia is responsible for soluble vascular endothelial growth factor receptor-1 (VEGFR-1) but not for soluble endoglin induction in villous trophoblast. Hum Reprod 2008;23(06):1407-1415. Doi: 10.1093/humrep/den114

35 Osol G, Celia G, Gokina N, et al. Placental growth factor is a potent vasodilator of rat and human resistance arteries. Am J Physiol Heart Circ Physiol 2008;294(03):H1381-H1387. Doi: 10.1152/ ajpheart.00922.2007

36 Schuitemaker JHN, Cremers TIFH, Van Pampus MG, Scherjon SA, Faas MM. Changes in endothelial cell specific molecule 1 plasma levels during preeclamptic pregnancies compared to healthy pregnancies. Pregnancy Hypertens 2018;12:58-64. Doi: 10.10 16/j.preghy.2018.02.012 